\title{
Evaluation and prediction of meteorological drought conditions using time-series and genetic programming models
}

\author{
Ebrahim Omidvar* and Zahra Nazeri Tahroodi \\ Faculty of Natural Resources and Earth Sciences, University of Kashan, Kashan, Iran. \\ *Corresponding author.e-mail: ebrahimomidvar@kashanu.ac.ir
}

MS received 23 June 2017; revised 22 June 2018; accepted 5 August 2018; published online 14 March 2019

Over the years, a number of prediction methods have been proposed for the evaluation of probability of hydrological-meteorological variables or drought indices. In this study, the precipitation data recorded in four stations of northwestern Iran over the period 1960-2014 were used to develop the time-series and genetic programming (GP) models. Comparison of the observed and predicted data showed that although both models have acceptable accuracy in predicting precipitation, the time-series models had lower errors than the GP models. So, the autoregressive and periodic autoregressive moving average models were chosen as the superior models for annual and monthly series, respectively. Therefore, the Standard Precipitation Index (SPI) and Z-Score Index (ZSI) were used to assess the drought conditions. According to the results, the SPI recognised a higher percentage of historical and prediction periods as drought conditions than ZSI. The validation of indices showed that the ZSI was more capable for detecting the drought and wetness conditions. The trend analysis of SPI and ZSI showed significant decreasing trends in different stations at all-time scales, except yearly in Urmia and all-time scales in Zanjan, which statically had no significant trend. In conclusion, given the current precipitation trends, the droughts are increasing in both severity and numbers.

Keywords. Time series; genetic programming; ZSI; SPI; northwest of Iran.

\section{Introduction}

According to the classification of American Meteorological Society (1997), droughts are divided into four types, namely meteorological, agricultural, hydrological and socioeconomic. The first three droughts are defined as deficit in precipitation, deficit in soil moisture and deficit in stream flow and reservoir storage, respectively (Maity et al. 2016). The hydrological cycle concerns the continuous transport of water, so meteorological droughts can be expected to propagate to other types of droughts (Maybank et al. 1995). Measuring precipitation is easier, more cost-effective and more accurate than measurements of soil moisture or runoff (Maity et al. 2016), and as a result, monitoring and prediction of meteorological droughts have the same benefits over monitoring and prediction of other types of drought.

Droughts can be studied using various indicators developed for this purpose such as Standard Precipitation Index (SPI) and Z-Score Index (ZSI). The SPI, which was developed by McKee et al. (1993), has been utilised in order to ascertain drought duration and severity (Paulo et al. 2005). 
The SPI may be computed in different time steps to facilitate the assessment of the effects of a precipitation deficit on different water resource components (soil moisture, groundwater, stream flow and reservoir storage). ZSI is a widely used drought indicator that does not require data to comply with gamma and Pearson distribution. As a result, this indicator is better suited to shortterm time scales (Edwards and Mckee 1997). ZSI has been extensively utilised for research for its easy calculations and high performance (Wu et al. 2001; Morid et al. 2006; Akhtari et al. 2009; Dogan et al. 2012; Jain et al. 2015). Many researchers have suggested that the ability of this index to predict droughts on different time scales is on par with Standardised Precipitation Index (SPI). This index also allows the researcher to replace the missing values in data series (Jain et al. 2015).

Drought condition and probability in different parts of the world including Iran is an extensively researched subject. A notable study of such nature on northwestern Iran is the work of Parsafar and Maroufi (2009) on Urmia's synoptic station for the period 1969-2005. Using the ZSI, they identified two extremely severe droughts, six severe droughts, four moderate droughts and six mild droughts for the aforementioned period. In another paper, Osmani (2009) used SPI on 30-yr data (1978-2007) of seven stations in northwestern Iran to evaluate the meteorological drought in this region. The results of this study showed that 1982 was the wettest year and 2001 was the driest year in this period.

Predicting the future occurrence of drought in a region is imperative for effective risk assessment and sustainable water management solutions. Over the years, a number of prediction techniques have been proposed for the evaluation of probability of hydrological-meteorological variables or drought indices. The notable methodologies used for this purpose include time-series modelling, neural network (NN), neuro-wavelet modelling and genetic programming (GP), among others. In recent years, linear GP has shown to be a convenient and successful modelling tool for water resource management applications. GP is a technique for automatic search for the solution of a problem through computer programming. This technique belongs to the family of evolutionary algorithms, which have shown good ability to model highly nonlinear and dynamic processes (Ahmadi et al. 2015). Utility of GP for water resource research application has been evaluated by various researchers. For example, Ahmadi et al. (2015) compared the performance of nonlinear time-series and GP models in predicting the daily flow of Barandozchay River in Urmia (northwestern Iran) over the period 1973-2009. Ultimately, these researchers concluded that GP model has a better river flow prediction capability than the time-series model. In another study, Hassanzadeh et al. (2012) used a combination of genetic algorithm (GA) and $\mathrm{NN}$-wavelet hybrid model to analyse and predict the drought indictor SPI in Tabriz station. Their results showed that GA provides better solutions than maximum likelihood method, and that using the mentioned hybrid method yields more desirable results than using the combination of NN and GA. Danandeh Mehr et al. (2014) studied the utility of GP in predicting the monthly flow of Çoruh River in Turkey. Their results showed that GP model has a better monthly flow prediction capability than three different models of artificial NN. The studies of Aytek and Asce (2008), Makkeasorn et al. (2008) and Guven (2009) on Schuylkill River (USA) have also confirmed the better accuracy of GP models than NNs. Notable studies in regard to application of time-series models in drought prediction and water resource research include the study of Zahedi et al. (2006), where monthly precipitation data of Urmia and Tabriz stations for a $50-y r$ period was processed to predict future precipitation data using the seasonal autoregressiveintegrated-moving-average (ARIMA) model. Their results showed that the selected model has a good performance in estimating the precipitation of the studied stations. Modarres (2007) also used a number of time-series models to predict the drought and flow of Zayandehrood River. His results demonstrated the utility of SARIMA timeseries models in prediction, design and management of water resources. Han et al. (2010) also used time-series models along with remote sensing data for prediction of drought in Guanzhong Plain (China). Ultimately, they concluded that for such data, the model $\mathrm{AR}(1)$ is more accurate than other time-series models. Saada (2014) evaluated the performance of a periodic autoregressive moving average (PARMA) model and temporal disaggregation models for forecasting the annual and monthly rainfall in Saudi Arabia. The results showed that these models performed good for modelling the monthly data, but the PARMA model did not have a high performance in yearly time scale. Escalante-Sandoval and Nuñez-Garcia (2017) predicted the yearly meteorological drought under 
different climate change scenarios in Mexico using PARMA model. Other notable works with similar approach include the studies of Momani and Naill (2009) on monthly precipitation data in Jordan, Mahsin et al. (2012) in Bangladesh, Meher and Jha (2013) on the Mahanadi river basin in India and Bazrafshan et al. (2015) on the Karkhe basin, all of which have shown the good performance of time-series models in predicting precipitation and drought indices over different time scales. Review of related literature shows that so far, no research has directly compared the performance of GP model and time-series model in predicting precipitation and meteorological drought index. Hence, in this study, first the performance of above-mentioned models in the study area was compared and then the superior models were used to examine and predict the condition of meteorological drought in this area over yearly and monthly time scales. Considering the importance of droughts in adopting appropriate management plans and also the lasting drought conditions in northwestern Iran over the recent years, the objective of this study was to investigate the drought condition in this area over the past half century and the future $10 \mathrm{yr}$ (i.e., from 1960 to 2024). Determining the climatic condition of the past and future years in this area can aid local and national authorities in developing programmes and policies tailored to the situation.

\section{Material and methods}

\subsection{Study area and data used}

This study was conducted using the annual and monthly precipitation recorded in four stations: Sanandaj, Tabriz, Urmia and Zanjan over the period 1960-2014. The profiles of the stations under study are shown in table 1. Based on UNESCO climate classification, these stations have a cold semi-arid climate. The geographical position of these stations is shown in figure 1 .

\subsection{Methods}

\subsubsection{Modelling of precipitation}

To predict the future drought condition in the study area, we first needed to predict the precipitation of studied stations in the coming years. To predict the precipitation, performance of GP and time-series models for this purpose was investigated. To verify the reliability of these models in predicting precipitation of future years, $82 \%$ of available data were used for training and the remaining $18 \%$ were used for validity assessment. Once the validity of models was verified and the superior model was identified, precipitation amounts of every station over the period 2014-2024 were predicted. Finally, the predicted precipitation data were used to predict the ZSI and SPI values over the next 10 yr (2014-2024).

Data normalisation: Typically, the use of raw data in time-series genetic and programming models undermines the speed and accuracy of the model. Therefore, data to be used in the model need to be normalised beforehand to avoid these issues. In this study, before modelling the precipitation data with time-series and GP, the annual and monthly precipitation data were normalised by equation (1) (Rajurkara et al. 2004):

$$
P_{\mathrm{n}}=0.1+\left[0.8\left(\frac{P_{\mathrm{O}}-P_{\min }}{P_{\max }-P_{\min }}\right)\right] .
$$

In equation $(1), P_{\mathrm{n}}$ is the normalised annual or monthly precipitation, $P_{\mathrm{O}}$ is the observed annual or monthly precipitation, and $P_{\max }$ and $P_{\min }$ are the maximum and minimum annual or monthly precipitations, respectively. According to equation (7), precipitation observations should be normalised to the range of $0.1-0.9$. Selecting 0.1 as the

Table 1. Geographic characteristic of the meteorological stations.

\begin{tabular}{lcccccc}
\hline & \multicolumn{2}{c}{ Longitude } & & \multicolumn{2}{c}{ Latitude } & \\
\cline { 2 - 3 } Station & Degree & Minute & & Degree & Minute & $\begin{array}{c}\text { Elevation } \\
(\mathrm{m})\end{array}$ \\
\hline Urmia & 45 & 5 & & 37 & 32 & 1312 \\
Tabriz & 46 & 17 & & 38 & 05 & 1361 \\
Sanandaj & 47 & 00 & & 35 & 20 & 1373 \\
Zanjan & 48 & 27 & & 36 & 41 & 1663 \\
\hline
\end{tabular}




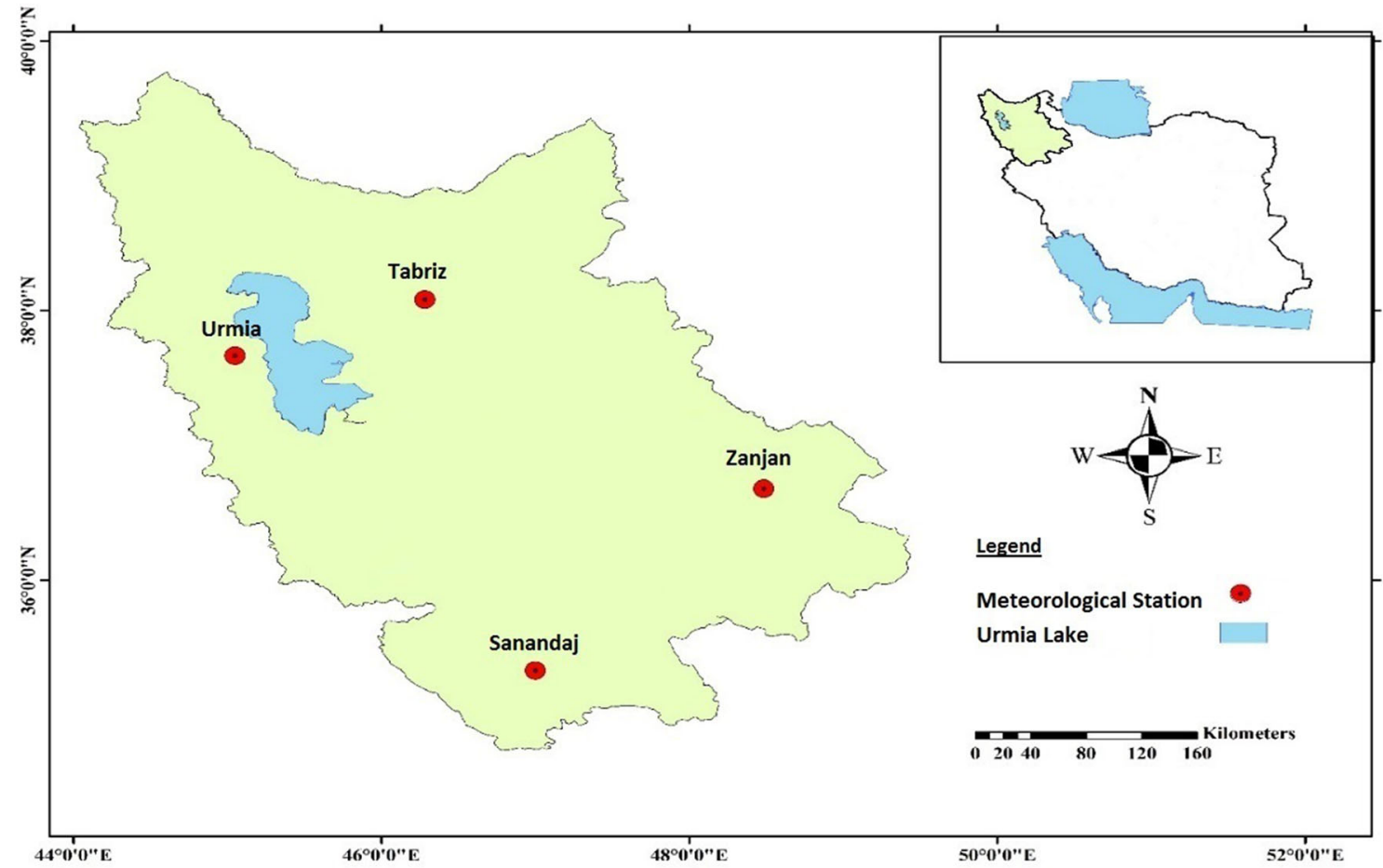

Figure 1. Geographical position of the stations is northwest of Iran.

minimum normalised precipitation value prevents the emergence of excessively small weights and thus premature saturation of neurons.

Time-series modelling: The first use of time series in hydrology dates back to early 1960s to a study by Thomas, Fiering and Ujevic. This application was later developed in 1970s by Box and Jenkin. The simplest type of time-series models is the autoregressive (AR) models operating based on Markov chain theory. A time series follows the Markov chain when every event occurred at time $t$ is related to the events occurred at preceding and following times $(t-i$ and $t+i)$. Other notable time-series models include autoregressive-movingaverage (ARMA) and ARIMA models (Salas et al. 1980). For a normal and standard time series $z_{t}$, ARMA has been defined as follows:

$$
Z_{t}=\sum_{i=1}^{p} \varphi_{i} z_{i-1}+\varepsilon_{t}-\sum_{j=1}^{q} \theta_{j} \varepsilon_{t-j}
$$

In the above equation, $p$ is the order of AR model, $q$ is the order of MA model, $\varphi_{i}$ and $\theta_{i}$ are the model coefficients and $\varepsilon_{t}$ is the error term sampled from a normal distribution with zero mean and variance of $\hat{\sigma}_{\varepsilon}^{2}$. Since some of time-series models such as ARMA and ARIMA cannot capture the structure of seasonal correlation despite the deletion of the seasonal effect, the PARMA model have been suggested for seasonal hydrologic time-series modelling (Shao et al. 2009). The $\operatorname{PARMA}(p, q)$ model has been defined as:

$$
Z_{V, \tau}=\sum_{j=1}^{P} \varphi_{j, \tau} Z_{v, \tau-1}-\sum_{i=1}^{P} \theta_{i, \tau} \varepsilon_{v, \tau-1}+\varepsilon_{v, \tau}
$$

where $\varphi$ 's and $\theta$ 's are the periodic AR coefficients of season $\tau$ and $\varepsilon$ is the error with mean zero and variance of $\sigma_{\tau}^{2}(\varepsilon)$. Since the marginal distribution of $Z$ is assumed to be standard normal, the distribution of $\varepsilon$ is also normal with mean zero and variance $\sigma_{\tau}^{2}(\varepsilon)$ (Marco et al. 2012).

Modelling with time-series approach requires a series of initial tests on time-series data. Since this model is going to be trained with preliminary data and the results of modelling and predictions are strongly based on this information, preliminary data must have no significant fluctuation, outlier, trend, jump, cycle, etc. Therefore, before modelling, data must be tested to establish the absence of such properties. For this purpose, the WaldWolfowitz method (runs test) was used to check the independence and the Wilcoxon method was used to investigate the homogeneity of data. One of the main objectives of the initial test is to examine the trends in data, so changes in data were investigated 
by the Mann-Kendall test, 3rd edition (Khalili et al. 2016). The trends identified in precipitation data were removed by differencing. Once data were made stationary by differencing, autocorrelation and partial autocorrelation tests were performed to make sure that seasonal effects are removed. Autocorrelation and partial autocorrelation diagrams of annual and monthly precipitation time series pertaining to each station were then plotted. Examination of these diagrams showed that in every four stations, autocorrelation approach zero indicating data series have been successfully made stationary and lack any seasonal changes.

For all stations in annual time series, type and order of the models were identified according to patterns of ACF and PACF values in the mentioned diagrams. ACF had a decreasing trend towards zero and PACF had a significant lag at the onset of the function, so models had AR patterns of order $p(A(p))$ (Wei 2006). For both monthly time series $\operatorname{PARMA}(p, q)$ pattern was applied, and for annual time series, the model's order was selected using the modified Akaike information criterion (AIC), as shown in equation (4):

$$
\operatorname{AIC}_{\mathrm{c}}(p, q)=n \ln \left(\hat{\sigma}_{t}^{2}\right)+\frac{2(p+q+1)}{(n-p-q-2)} .
$$

In the above equation, $p$ and $q$ are the model orders and $\hat{\sigma}_{\varepsilon}^{2}$ is the variance of time-series residual (Salas et al. 1980). The best model is the one with the lowest $\mathrm{AIC}_{\mathrm{C}}$ value.

Genetic programming: GP is an iterative algorithm based on Darwin's theory of evolution. Iterative algorithms first define an objective function based on qualitative criteria, and then use this function iteratively to compare the solutions obtained by modification of data structure, and continue this procedure until finding a desirable solution. GP is the newest method among evolutionary algorithms and has found many applications because of its desirable accuracy (Alvisi et al. 2006). The steps of GP modelling are described below (Borelli et al. 2006):

(1) Randomly generate an initial population of functions representing prediction models.

(2) Evaluate every member of population using the fitness functions.

(3) In each generation, use the following steps to produce the members of a new population:

A: Select one of the operators: crossover, mutation or copy.
B: Select an appropriate number of members of population.

C: Use the selected operator to produce an offspring.

D: Assign the produced offspring to the new population.

E: Evaluate the model using the fitness functions.

(4) Repeat Step 3 until reaching a maximum number of iterations.

In GP, calculations are based on the crossover, mutation and permutation operators, which are applied directly on the parse trees. The most frequently used among the above operators is the crossover. Crossover operator is a method for randomised combining of two or several fit solutions to produce new and potentially fitter solutions. Often, crossover is the only exploratory operator used in GP. In the case of GP, to create a new offspring, a number of branches of the two parent trees will be randomly swapped. The purpose of this operator is to turn the solutions of lower order into more complex solutions with rule-wise correct structure.

Performance evaluation: To determine the superior model between the time-series and GP models, performance of models was evaluated by three criteria: root mean square error (RMSE), coefficient of determination $\left(r^{2}\right)$ and Nash-Sutcliffe efficiency (NS).

(a) Root mean square error

$$
\operatorname{RMSE}=\left[\frac{\sum_{i=1}^{n}\left(o_{i}-P_{i}\right)^{2}}{n-1}\right]^{0.5} .
$$

The lowest RMSE value represents the best performance of the model (Salas et al. 1980).

(b) Coefficient of determination $r^{2}$

The values of $r^{2}$ are between 0 and 1. A value of zero indicates no correlation at all, whereas a value of 1 indicates that the dispersion of the prediction is equal to that of the observation. $r^{2}$ can be calculated as below (McCuen 1989):

$$
r^{2}=\left[\frac{\sum_{i=1}^{n}\left(P_{i}-\bar{P}\right)\left(O_{i}-\bar{O}\right)}{\sqrt{\sum_{i=1}^{n}\left(P_{i}-\bar{P}\right)^{2} \times \sqrt{\sum_{i=1}^{n}\left(O_{i}-\bar{O}\right)^{2}}}}\right] .
$$


Table 2. Classification of dry or wet condition based on SPI and ZSI

(Jain et al. 2015) and scoring for worst drought and wettest years.

\begin{tabular}{lccc}
\hline Classes & SPI and ZSI & $\begin{array}{c}\text { Score for worst } \\
\text { drought year }\end{array}$ & $\begin{array}{c}\text { Score for } \\
\text { wettest years }\end{array}$ \\
\hline Extremely wet & $\geq 2$ & -20 & 20 \\
Very wet & $1.5-1.99$ & -15 & 15 \\
Moderately wet & $1-1.99$ & -10 & 10 \\
Normal & -0.99 to 0.99 & 1 & 1 \\
Moderately dry & -1.49 to -1 & 10 & -10 \\
Severely dry & -1.99 to -1.5 & 15 & -15 \\
Extremely dry & $\leq-2$ & 20 & -20 \\
\hline
\end{tabular}

(c) Nash-Sutcliffe efficiency

$$
\mathrm{NS}=1-\frac{\sum_{i=1}^{n}\left(O_{i}-P_{i}\right)^{2}}{\sum_{i=1}^{n}\left(O_{i}-\bar{O}\right)^{2}} .
$$

The range of NS is between $-\infty$ and 1 (good fit). A negative value of $\mathrm{NE}$ means that the mean value of the observed time series would have been a better predictor than the model (Krause et al. 2005).

In the above equations, $n$ is the number of data, $O_{i}$ denotes the observed data, $P_{i}$ denotes the predicted data, and $\bar{O}_{i}$ and $\overline{P_{i}}$ are their means, respectively.

\subsubsection{Drought indices}

As droughts were regional in nature and extend for long periods of time, it was important to study such events within a regional context and long term (Suryabhagavan 2017). In the present study, recorded and predicted precipitation data were used to determine the yearly and monthly values of ZSI and SPI for the historic (1960-2014) and future (2014-2024) periods.

In its original version of SPI a long precipitation record at a station is fitted to a probability $(\gamma)$ distribution, which is then transformed into a normal distribution so that the mean SPI is zero. The index values are, therefore, the standardised deviations of the transformed rainfall totals from the mean (Smakhtin and Hughes 2007).

The ZSI was computed using the following formula:

$$
\mathrm{ZSI}=\frac{p_{i}-\bar{p}}{\mathrm{Sd}}
$$

where $P_{i}$ is the amount of precipitation during current year or month $(i), \bar{P}$ and $\mathrm{Sd}$ are the mean and standard deviation of precipitation data. For trend analysis of drought indices over the future (2014-2024), we had to calculate the drought indices on a long-term basis, not for a period of 10 yr. So, $\bar{P}$ and Sd were calculated separately for the historical (1960-2014) and prediction periods (1960-2024). ZSI, in fact, shows the extent that standard deviation of precipitation is higher or lower than its mean value (Dogan et al. 2012). A positive ZSI indicates a more than average precipitation and a negative value indicates the opposite.

Accordingly, a drought occurs when SPI and ZSI are continuously negative and reach a value of -1 or less, and end when SPI and ZSI become positive (table 2).

\subsubsection{Trend analysis of drought and precipitation data}

The Mann-Kendall test was performed at 5\% confidence level to determine the trend of changes in precipitation, SPI and ZSI values at historical and prediction periods. A test statistic is less than $\alpha$ value shows that studied data have no particular trend, and a test statistic, i.e., greater than $\alpha$-value indicates the opposite. The gradient of the trend shows the amount of increase or decrease when compared with the studied period (Khalili et al. 2016).

\subsubsection{Validation of predicted drought conditions}

In order to validate predicted drought conditions by SPI and ZSI, and comparison of these indices, at first, the wettest and worst drought years have been identified in the study area over the past $50 \mathrm{yr}$ by reviewing of the literature and government reports. Previous studies on meteorological droughts in northwestern Iran showed that, in general, 1989, 1995 and 2001 were known as worst drought years and, 1982, 1993, 1994 and 2004 are 
known as wettest years in the region (Osmani 2009; Salahi and Faridpour 2016; Javanmard et al. 2017). Then, considering the predicted drought conditions of these years based on SPI and ZSI at prediction period, a score was given to each index. The best performance is when the index predicts an extremely drought condition for worst drought year and an extremely wet condition for the wettest year. The scoring procedure for drought and wet conditions is showed in table 1. Finally, the total score of each index was calculated at all stations and years.

\section{Results and discussion}

\subsection{Precipitation time series}

Annual and monthly precipitation data for four stations Sanandaj, Tabriz, Urmia and Zanjan were investigated. Figures 2 and 3 illustrate the annual and monthly time series of precipitation in the studied stations over the historical period (19602014). Among the studied stations, Sanandaj (439.5 $\mathrm{mm})$ and Zanjan $(328.6 \mathrm{~mm})$ have had the
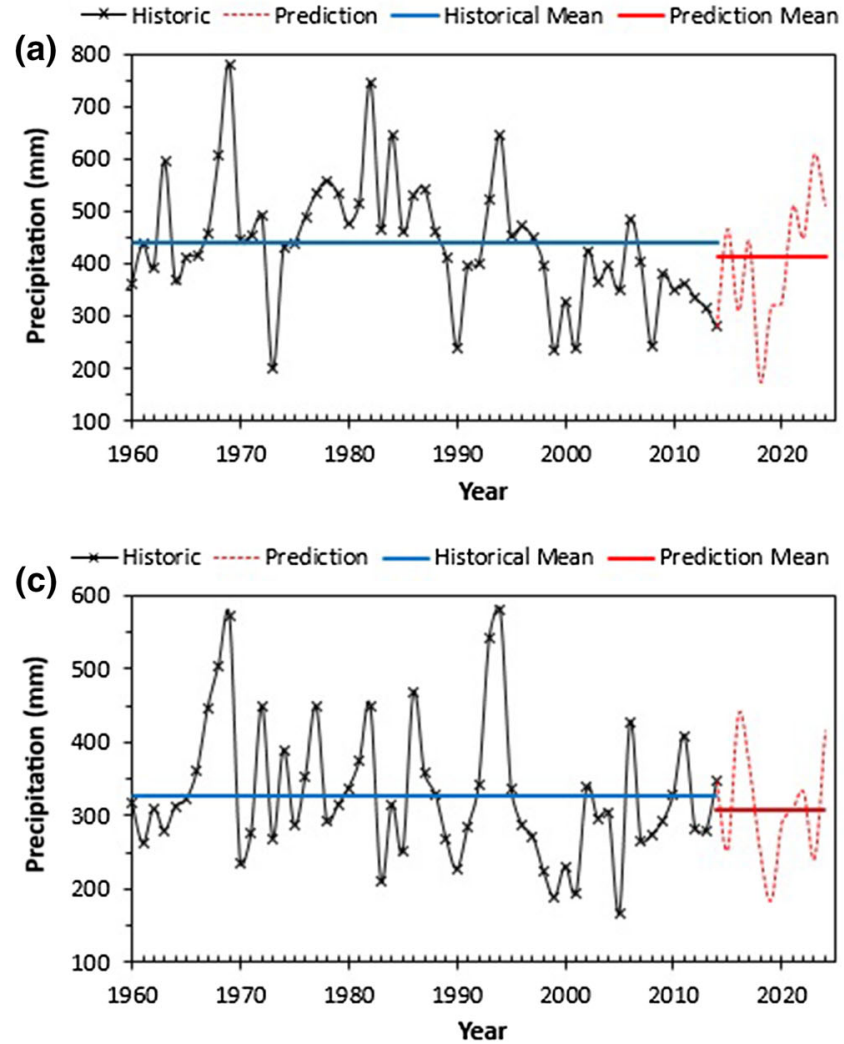

highest and lowest mean precipitation values over the historical period. The results show a reduced rate of precipitation from 1999 in Sanandaj station and from 1995 in other stations. The calculated Mann-Kendal statistics and the Sen's slope of annual and monthly precipitation in historical period are shown in table 3. Examining the trend of changes in annual precipitation showed a decreasing trend in the studied stations, these results revealed a significant negative trend (at 1\% confidence level) in Tabriz and Sanandaj stations and an insignificant decreasing trend in Urmia and Zanjan stations. The trend analysis of monthly precipitation in historical period suggested that the Tabriz station had a significant negative trend at $1 \%$ confidence level but in the Sanandaj, Urmia and Zanjan stations there were no statistically significant trend (table 3 ).

\subsection{Modelling of precipitation data}

\subsubsection{Modelling with time-series approach}

To investigate the meteorological drought indices of the study area over the historical period (used
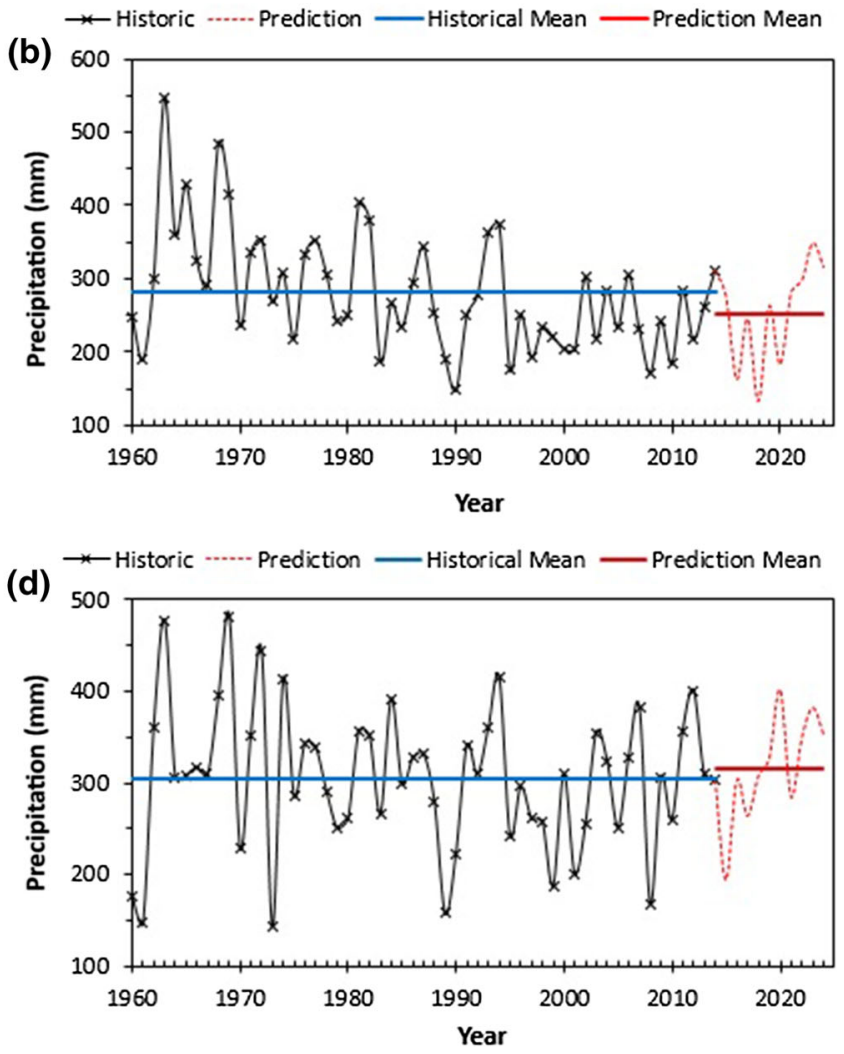

Figure 2. The annual precipitation in historical period (1960-2014) and predicted by time-series models (2014-2024) for (a) Sanandaj, (b) Tabriz, (c) Urmia and (d) Zanjan. 

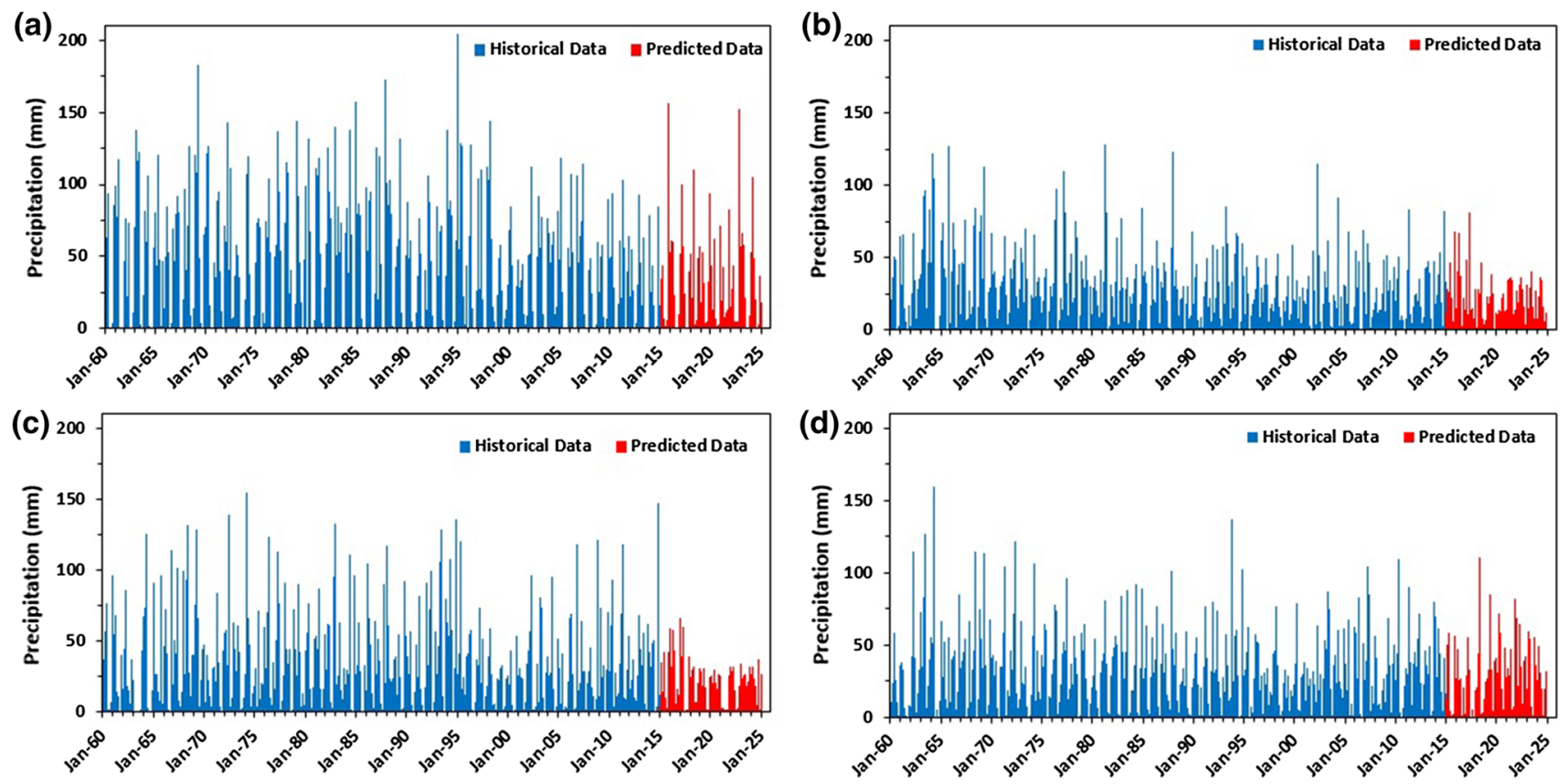

Figure 3. The monthly precipitation in historical period (1960-2014) and predicted by time-series models (2014-2024) for (a) Sanandaj, (b) Tabriz, (c) Urmia and (d) Zanjan.

Table 3. Trend analysis of annual and monthly precipitation in historical period (1960-2014) with Mann-Kendal test.

\begin{tabular}{lcccccc}
\hline & \multicolumn{3}{c}{ Annual series } & & \multicolumn{2}{c}{ Monthly series } \\
\cline { 2 - 4 } \cline { 6 - 7 } Stations & Mean & $\alpha$-value & Trend slope & & $\alpha$-value & Trend slope \\
\hline Sanandaj & 439.5 & 0.002 & -2.751 & & 0.074 & 0.000 \\
Tabriz & 281.6 & 0.002 & -2.04 & & 0.008 & -0.008 \\
Urmia & 328.6 & 0.212 & -0.803 & & 0.213 & -0.002 \\
Zanjan & 305.1 & 0.442 & -0.507 & & 0.836 & 0.000 \\
\hline
\end{tabular}

modelling and validation) and the prediction period, first, the annual and monthly precipitation data of the stations were studied and fitted using the GP and time-series models, then the superior model was used to the precipitation data for the 10-yr-period ending at 2024. Examining the predictions of linear time-series models for the annual precipitation in the study area showed that, according to Akaike criterion, the model $\operatorname{AR}(2)$ is the best choice for modelling of annual precipitation data pertaining to Sanandaj station. According to Akaike criterion, the model AR(1) was found to be the best choice for modelling of annual precipitation data of Urmia, Zanjan and Tabriz stations. Error and accuracy of these models are shown in table 4. As mentioned, the data pertaining to the last $10 \mathrm{yr}$ of historical period were used to verify the validity and accuracy of the models. For this purpose, this $10-y r$ period was removed from historical time series, data of this period predicted by the developed models, and the predictions were compared with the observed values. $r^{2}$, RMSE and NS obtained for the family of ARMA models showed the high accuracy of the selected models modelling and prediction of annual precipitation data of the studied stations. As mentioned in the methodology, the several PARMA models were evaluated to model the monthly time series. The results showed that $\operatorname{PARMA}(0,1)$ was the best-fit model based on Akaike criterion for all stations. At all stations, the PARMA model has an acceptable accuracy $\left(0.949<r^{2}\right.$ and $\left.0.897<\mathrm{NS}\right)$, both at the training and testing stages (table 4 ).

Comparison of the time-series models performance in annual and monthly time scales at all four stations indicated that the monthly PARMA model with a higher acceptance ratio of the performance evaluation indices appears to be better than the annual AR model in both training and test stages (table 4). This result is consistent with 
Table 4. Error and accuracy of time-series and genetic programming models in the prediction of annual and monthly precipitation.

\begin{tabular}{|c|c|c|c|c|c|c|c|c|}
\hline \multirow[b]{2}{*}{ Station } & \multirow[b]{2}{*}{ Time scale } & \multirow[b]{2}{*}{ Model } & \multicolumn{3}{|c|}{ Training } & \multicolumn{3}{|c|}{ Test } \\
\hline & & & $r^{2}$ & RMSE & NS & $r^{2}$ & RMSE & NS \\
\hline \multirow[t]{4}{*}{ Sanandaj } & Annual & $\operatorname{AR}(2)$ & 0.908 & 364.44 & 0.898 & 0.741 & 32.12 & 0.714 \\
\hline & & GP & 0.920 & 387.23 & 0.811 & 0.821 & 33.01 & 0.782 \\
\hline & Monthly & $\operatorname{PARMA}(0,1)$ & 0.996 & 3.926 & 0.990 & 0.993 & 3.770 & 0.985 \\
\hline & & GP & 0.987 & 6.851 & 0.972 & 0.979 & 6.634 & 0.954 \\
\hline \multirow[t]{4}{*}{ Tabriz } & Annual & $\operatorname{AR}(1)$ & 0.889 & 278.54 & 0.976 & 0.935 & 23.17 & 0.960 \\
\hline & & GP & 0.901 & 308.23 & 0.830 & 0.895 & 28.83 & 0.870 \\
\hline & Monthly & $\operatorname{PARMA}(0,1)$ & 0.964 & 6.602 & 0.925 & 0.949 & 6.329 & 0.897 \\
\hline & & GP & 0.929 & 9.374 & 0.850 & 0.904 & 8.760 & 0.802 \\
\hline \multirow[t]{4}{*}{ Urmia } & Annual & $\operatorname{AR}(1)$ & 0.850 & 405.57 & 0.923 & 0.883 & 25.64 & 0.907 \\
\hline & & GP & 0.887 & 408.34 & 0.713 & 0.933 & 33.98 & 0.812 \\
\hline & Monthly & $\operatorname{PARMA}(0,1)$ & 0.982 & 5.760 & 0.963 & 0.982 & 5.608 & 0.962 \\
\hline & & GP & 0.963 & 8.469 & 0.921 & 0.961 & 8.175 & 0.920 \\
\hline \multirow[t]{4}{*}{ Zanjan } & Annual & $\operatorname{AR}(1)$ & 0.857 & 209.96 & 0.966 & 0.903 & 21.26 & 0.928 \\
\hline & & GP & 0.812 & 316.12 & 0.821 & 0.945 & 28.57 & 0.913 \\
\hline & Monthly & $\operatorname{PARMA}(0,1)$ & 0.982 & 4.877 & 0.964 & 0.982 & 4.697 & 0.963 \\
\hline & & GP & 0.958 & 7.638 & 0.911 & 0.952 & 7.560 & 0.904 \\
\hline
\end{tabular}

Saada (2014) who reported a better performance in monthly PARMA compared to annual time-series model.

\subsubsection{Modelling with genetic programming approach}

The accuracy of the GP model was also investigated. Before modelling with this approach, the annual precipitation data were first normalised. Like before, the last $10 \mathrm{yr}$ of available data were reserved for model validation. The results of GP model in modelling and prediction of annual and monthly precipitation data in two phases of training and testing stations are presented in table 4 . The data were examined with various different lags and ultimately the model with lowest RMSE was chosen as the best. The results of annual GP modelling for different stations showed that, with $r^{2}$ and NS considered as evaluation measures, Sanandaj station in the training phase and Zanjan station in the testing phase have the most desirable data structures. In addition, the statistical performance indices for GP monthly modelling suggested that that the GP models are capable of predicting precipitation.

Like the time-series models, the performance indices of the monthly GP models in comparison to the annual GP models were more satisfactory. For example, in Sanandaj station, the NS and $r^{2}$ of best-fit GP model for monthly series were 0.979 and 0.954 , respectively, whereas for annual series, the NS and $r^{2}$ were 0.782 and 0.821 , respectively. The same procedure can be seen in other stations also (table 4).

\subsubsection{Precipitation prediction using the fittest model}

The results regarding the accuracy of GP and timeseries models in predicting annual precipitation data showed that in almost all cases, coefficient of determination (between actual and predicted values) of GP model was higher than that of linear time-series model, but RMSE and NS of linear time-series model are, respectively, lower and higher than that of GP model. Since RMSE and NS (model error) are better accuracy evaluation measures than coefficient of determination, linear time-series model was selected as the superior model for predicting of annual precipitation. Comparison of time-series and GP models based on $r^{2}$, NS and RMSE criteria in monthly series showed that PARMA time-series model has higher performance at all stations. Note that the difference between these two models was insignificant, but given the importance of modelling and predicting the hydrological parameters, the slightest difference between models should also be considered. Generally, the results of this study on the modelling 
and prediction of annual and monthly precipitation values showed the satisfactory prediction performance of both models. This result is inconsistent with the results of Ahmadi et al. (2015) regarding the prediction performance of these two models for daily flows. Also, some studies including those by Aytek and Asce (2008), Makkeasorn et al. (2008), Guven (2009), Hassanzadeh et al. (2012) and Danandeh Mehr et al. (2014) have reported the good performance of GP and algorithms in predicting drought and river flow values, which support the result of present study.

The more preferable result of time-series models for Urmia and Tabriz stations is consistent with the results of Zahedi et al. (2006). In addition, the good prediction performance of time-series models is in agreement with the reports of Modarres (2007), Momani and Naill (2009), Han et al. (2010), Mahsin et al. (2012) in Bangladesh, Meher and Jha (2013) and Bazrafshan et al. (2015).

After verifying the accuracy of time-series model, annual and monthly precipitation values in the studied stations over the next 10 yr (2014-2024) were predicted. The historical data and the predictions made by these models for annual and monthly time series are presented in figures $2 \mathrm{a}-\mathrm{d}$ and $3 \mathrm{a}-\mathrm{d}$, respectively.

According to the precipitation predications made using the time-series model, despite fluctuations in annual precipitation values over the future period, in Sanandaj, Tabriz and Urmia, they were averagely lower than the values recorded in the historical period (figure $2 \mathrm{a}-\mathrm{d}$ ). On the monthly basis, the results of models prediction at all stations showed that monthly precipitation has decreased during the future period compared to the historical period (figure $3 \mathrm{a}-\mathrm{d}$ ).

\subsection{Drought prediction using the time-series model}

After model evaluation, the time-series model was used on precipitation data gathered in the studied stations over a 65-yr period and the SPI and ZSI in the 3-, 6-, 9-month and yearly time scales were calculated over historical (1960-2014) and prediction periods (1960-2024). The result of SPI and ZSI values showed the more frequency of drought starting from 1999 in Sanandaj station and starting from 1995 in Tabriz, Urmia and Zanjan stations. According to the obtained ZSI values, in the studied stations, the number of near normal years over the past half century has been higher than the number of drought years.
Box plots of 3-, 6- and 9-month SPI and ZSI showed that both indices at all stations predict the drought index value in the 25 th percentile, median, and 75 th percentile in the range of normal condition ( -1 to 1$)$. The worst droughts during the predicted period (1960-2024) among the studied stations varied in terms of drought index and time scale. In a 3-month time scale, the worst droughts based on ZSI and SPI occurred in Sanandaj and Zanjan, respectively; in a 6-month time scale, the worst drought based on both ZSI and SPI occurred in Urmia; and in a 9-month time scale, the worst drought based on ZSI and SPI occurred in Sanandaj and Urmia stations (figure $4 \mathrm{a}-\mathrm{c}$ ).

Examination of changes in yearly SPI and ZSI of stations over the period 1960-2024 showed the worst drought to be in Zanjan stations. Also, based on the SPI and ZSI results the wettest years were in Tabriz and Zanjan stations, respectively. However, given the median and 75th percentile SPI and ZSI illustrated in the box plots of figure 4(d), over the course of prediction period, drought severity will remain within the normal range. Comparison of the two indices showed that at all stations SPI drought values were less than ZSI.

Investigation of drought conditions of Sanandaj based on SPI and ZSI in the historical (1960-2014) and future period (2014-2024) showed that most years and months of the historical period were close to normal drought condition, except for the yearly time scale which will face extremely and severely dry over $60 \%$ of the years in the future period. Distribution pattern of wet and dry years in both the periods indicated that the percentage of years and months with moderately, severely and extremely dry conditions in the future period is more than the historical period (figure 5a).

In Tabriz station, like Sanandaj, most years and months of the historical period have had a close to normal SPI and ZSI. For example, in this period (1960-2014), based on yearly SPI and ZSI, respectively, $5.45 \%$ and $14.54 \%$ of the years have had a lower than normal precipitation (dry condition), $32.73 \%$ and $14.54 \%$ of the years have had a higher than normal precipitation (wet condition), and $61.82 \%$ and $70.09 \%$ of the years have had a close to normal condition. The result obtained for this station showed that distribution of drought condition in the future period (2014-2024) based on yearly SPI and ZSI is different from the historical period, as $30 \%$ and $30 \%$ of the years of this period have been dry, $0 \%$ and $10 \%$ of the years of this period have 

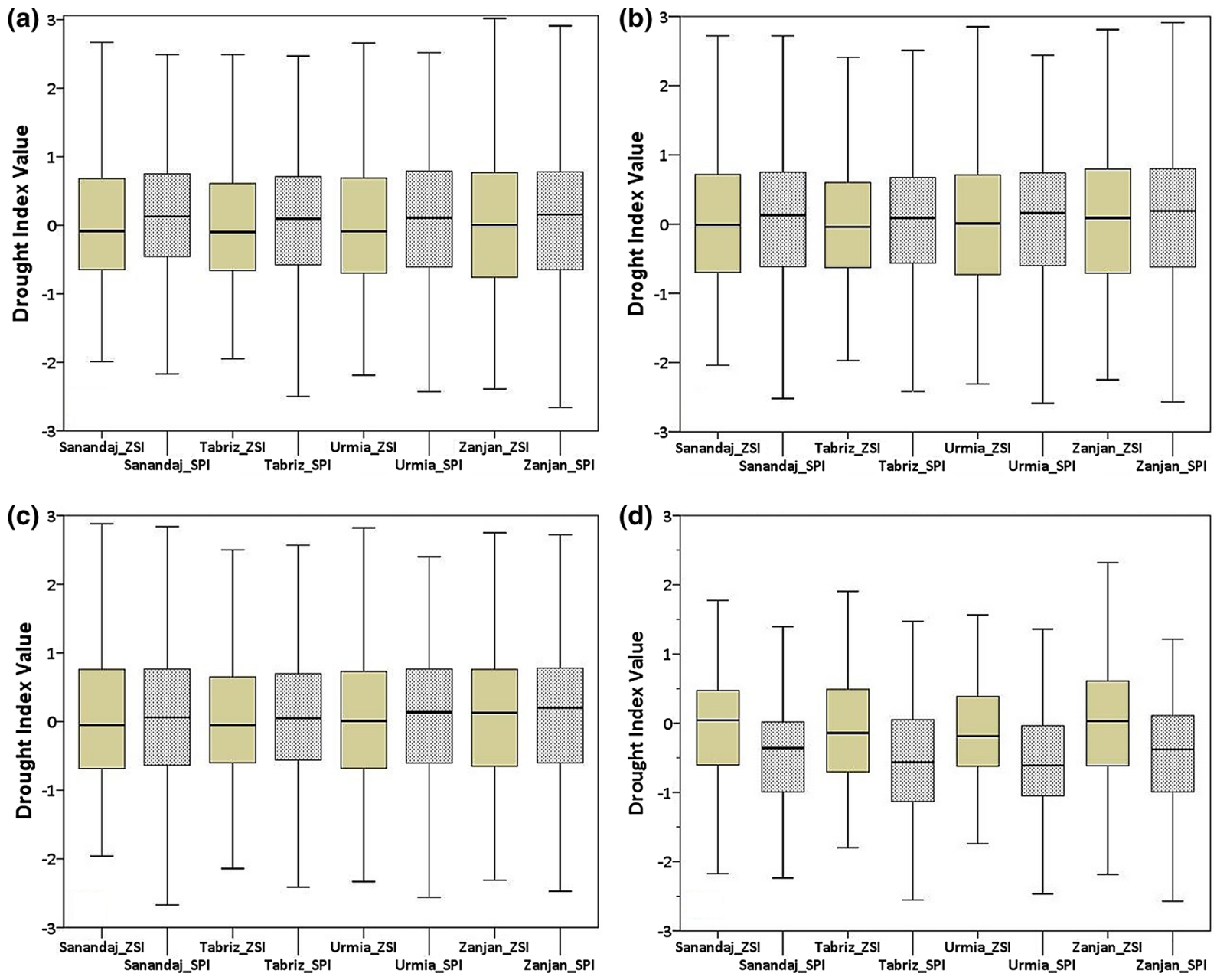

Figure 4. Box plots of ZSI and SPI values in the studied stations at prediction period (1960-2024) for (a) 3 months, (b) 6 months, (c) 9 months and (d) annual time scales.

been wet, and $70 \%$ and $60 \%$ of the years of this period have experienced a close to normal condition. Monthly SPI and ZSI (3-, 6- and 9-month) showed that the fraction of drought conditions during the future period is more than the historical period (figure $5 \mathrm{~b}$ ).

The results showed that over the historical period (1965-2014) Urmia station has experienced 15 (4 extremely, 3 severely and 8 moderately dry conditions) and 7 (4 extremely and 3 moderately dry conditions) yearly droughts, as defined by SPI and ZSI, respectively. However, Parsafar and Maroufi (2009) have reported that based on ZSI, Urmia has experienced 18 droughts (2 extremely, 6 severely, 4 moderately and 6 mild dry conditions) over the period 1969-2005. This difference in the number of drought years could be due to the differences in the number of studied years because the precipitation values and consequently the total mean and standard deviation of the data could vary with the number and precipitation amounts of years considered in the calculations.

The result obtained for Urmia synoptic station showed that like the above cases, most years and months of the historical period have had a close to normal SPI and ZSI. In this period (1960 2014), based on yearly SPI and ZSI, respectively, $27.69 \%$ and $10.91 \%$ of the years have experienced drought conditions and about $6.15 \%$ and $16.36 \%$ of the years have had wet conditions. Examining the drought indices for this station showed that the number of wet years in this period is higher than the number of droughts years, as defined by ZSI, and vice versa the number of wet years was lower than the dry ones as, defined by SPI. Also, most of the years and months of this period have had a normal condition based on SPI and ZSI. In the future period (2014-2024), the percentage of monthly and yearly drought conditions based on 

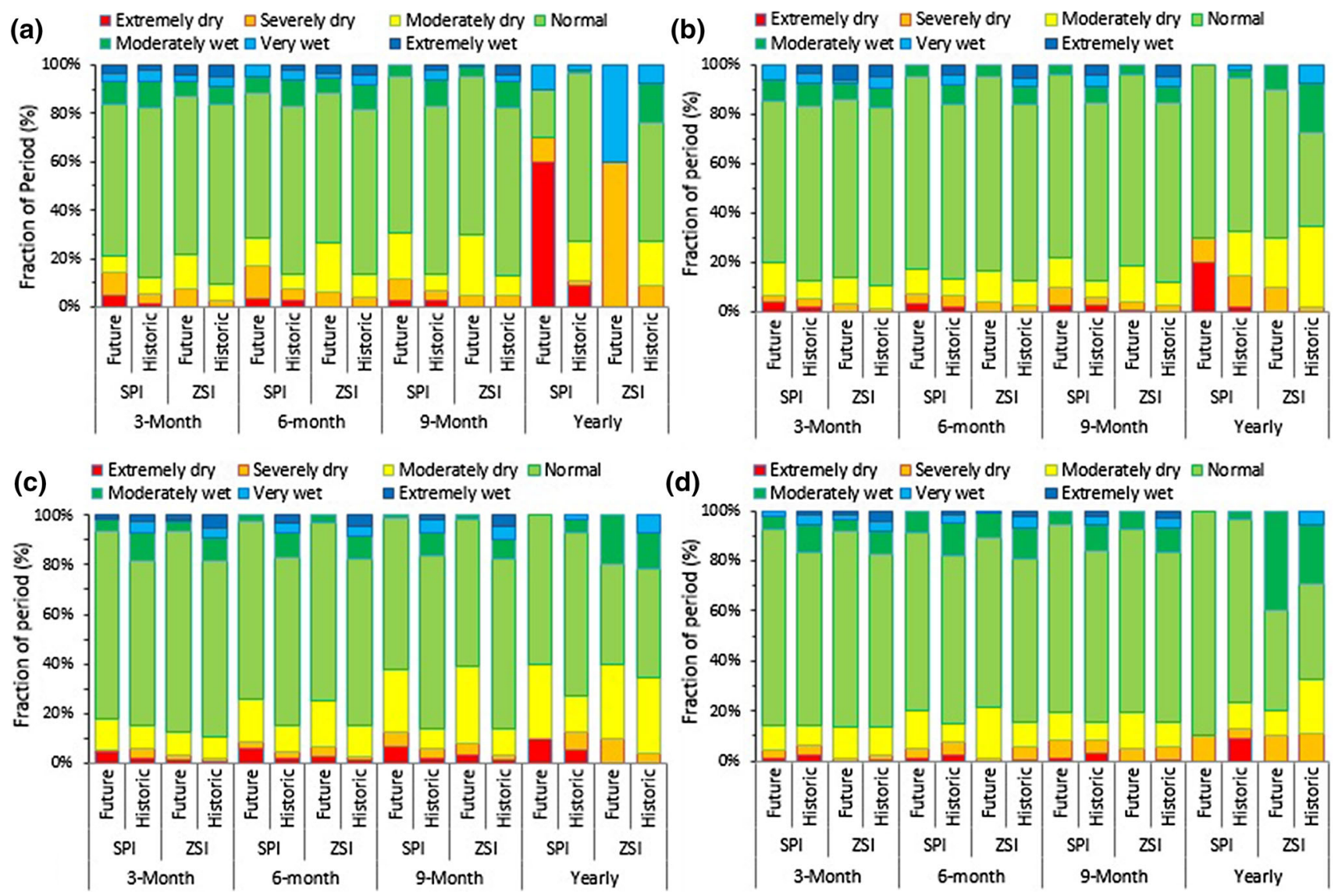

Figure 5. Drought condition fraction of the historic (1960-2014) and future (2014-2024) periods for (a) Sanandaj, (b) Tabriz, (c) Urmia and (d) Zanjan.

both SPI and ZSI is more than before, this means that droughts have been more severe. Therefore, future period shows a lower number of wet months and years. According to results, in this station, two studied periods have had almost the same percentage of months and years with normal condition as defined by SPI and ZSI (figure 5c).

The results obtained for Zanjan synoptic station for the two studied periods (historic and future) based on ZSI and SPI are similar to the results described above (figure $5 \mathrm{~d}$ ).

Overall, according to the results of figures 4 and 5, a comparison of the drought severity defined by SPI and ZSI indices at all stations showed that SPI recognised a higher percentage of historical and prediction periods as drought conditions (extremely, severely and moderately dry conditions) than ZSI. Conversely, ZSI detected a higher percentage of both periods as wet conditions (moderately, very and extremely wet conditions) than SPI.

The results of the Mann-Kendall test on trends of ZSI and SPI in historical and prediction periods are shown in table 5. The test statistic for $\alpha=$ 0.05 and also the Sen's slope of changes are presented. According to the results in the historical and prediction periods, the trends of ZSI and SPI in Sanandaj and Tabriz stations at all-time scales showed a decreasing slope with significance at 0.01 level, except yearly ZSI in prediction period which had significance at 0.05 level. The trends of monthly ZSI and SPI in Urmia stations were similarly decreasing at 0.01 significance level, but in yearly time scale both indices trends were not statically significant, except ZSI in prediction period which had a trend with the significance at 0.05 level. Other results showed that in the trends of ZSI and SPI of Zanjan station were statically not significant.

The validation of indices to predict drought conditions in the worst drought years $(1989,1995,2001$ and 2008) showed that moderately to extremely dry condition was expected in all cases except the condition in 2008 at Urmia by SPI. In the case of wettest years (1982, 1993, 1994 and 2004), the conditions between normal to very wet were 
Table 5. Trend analysis of ZSI and SPI values in historical (1960-2014) and prediction (1960-2024) periods with MannKendal test.

\begin{tabular}{|c|c|c|c|c|c|c|c|c|c|}
\hline \multirow[b]{2}{*}{ Time scale } & \multirow[b]{2}{*}{ Stations } & \multicolumn{2}{|c|}{ Historical ZSI } & \multicolumn{2}{|c|}{ Historical SPI } & \multicolumn{2}{|c|}{ Prediction ZSI } & \multicolumn{2}{|c|}{ Prediction SPI } \\
\hline & & $\alpha$-value & Trend slope & $\alpha$-value & Trend slope & $\alpha$-value & Trend slope & $\alpha$-value & Trend slope \\
\hline \multirow[t]{4}{*}{3 months } & Sanandaj & 0.0001 & -0.0007 & 0.0001 & -0.0007 & 0.0001 & -0.0007 & 0.0001 & -0.0008 \\
\hline & Tabriz & 0.0001 & -0.0011 & 0.0001 & -0.0011 & 0.0001 & -0.0009 & 0.0001 & -0.0009 \\
\hline & Urmia & 0.053 & -0.0004 & 0.037 & -0.0004 & 0.0001 & -0.0007 & 0.0001 & -0.0008 \\
\hline & Zanjan & 0.9390 & 0.0000 & 0.909 & 0.0000 & 0.3314 & -0.0001 & 0.3082 & -0.0002 \\
\hline \multirow[t]{4}{*}{6 months } & Sanandaj & 0.0001 & -0.0012 & 0.0001 & -0.00125 & 0.0001 & -0.0013 & 0.0001 & -0.0013 \\
\hline & Tabriz & 0.0001 & -0.0016 & 0.0001 & -0.0017 & 0.0001 & -0.0013 & 0.0001 & -0.0014 \\
\hline & Urmia & 0.0018 & -0.0007 & 0.0012 & -0.0007 & 0.0001 & -0.0011 & 0.0001 & -0.0011 \\
\hline & Zanjan & 0.0783 & -0.0004 & 0.0809 & -0.0004 & 0.0112 & -0.0004 & 0.0104 & -0.0004 \\
\hline \multirow[t]{4}{*}{9 months } & Sanandaj & 0.0001 & -0.0016 & 0.0001 & -0.0016 & 0.0001 & -0.0017 & 0.0001 & -0.0018 \\
\hline & Tabriz & 0.0001 & -0.0020 & 0.0001 & -0.0021 & 0.0001 & -0.0017 & 0.0001 & -0.0018 \\
\hline & Urmia & 0.0002 & -0.0008 & 0.0002 & -0.0008 & 0.0001 & -0.0014 & 0.0001 & -0.0014 \\
\hline & Zanjan & 0.0109 & -0.0006 & 0.0088 & -0.0006 & 0.0007 & -0.0006 & 0.0005 & -0.0006 \\
\hline \multirow{4}{*}{ Yearly } & Sanandaj & 0.008 & -0.026 & 0.002 & -0.022 & 0.011 & -0.027 & 0.009 & -0.016 \\
\hline & Tabriz & 0.001 & -0.028 & 0.002 & -0.024 & 0.002 & -0.031 & 0.005 & -0.018 \\
\hline & Urmia & 0.074 & -0.013 & 0.212 & -0.008 & 0.009 & -0.016 & 0.180 & -0.007 \\
\hline & Zanjan & 0.253 & -0.011 & 0.442 & -0.006 & 0.690 & -0.012 & 0.879 & -0.0006 \\
\hline
\end{tabular}

Table 6. Validation of predicted yearly drought conditions in the worst drought and wettest years with previous studies (Osmani 2009; Salahi and Faridpour 2016; Javanmard et al. 2017).

\begin{tabular}{|c|c|c|c|c|c|c|c|c|c|c|}
\hline \multirow[b]{2}{*}{ Station } & \multirow[b]{2}{*}{ Drought indices } & \multicolumn{4}{|c|}{ Worst drought year } & \multicolumn{4}{|c|}{ Wettest year } & \multirow[b]{2}{*}{ Sum of scores } \\
\hline & & 1989 & 1995 & 2001 & 2008 & 1982 & 1993 & 1994 & 2004 & \\
\hline \multirow[t]{4}{*}{ Sanandaj } & SPI & $* \mathrm{ED}$ & $\mathrm{MD}$ & $\mathrm{ED}$ & ED & MW & $\mathrm{N}$ & $\mathrm{N}$ & $\mathrm{N}$ & 83 \\
\hline & & 20 & 10 & 20 & 20 & 10 & 1 & 1 & 1 & \\
\hline & ZSI & $\mathrm{SD}$ & $\mathrm{MD}$ & $\mathrm{SD}$ & $\mathrm{SD}$ & VW & MW & VW & $\mathrm{N}$ & 96 \\
\hline & & 15 & 10 & 15 & 15 & 15 & 10 & 15 & 1 & \\
\hline \multirow[t]{4}{*}{ Tabriz } & SPI & $\mathrm{ED}$ & $\mathrm{SD}$ & $\mathrm{MD}$ & $\mathrm{SD}$ & MW & $\mathrm{N}$ & $\mathrm{N}$ & $\mathrm{N}$ & 73 \\
\hline & & 20 & 15 & 10 & 15 & 10 & 1 & 1 & 1 & \\
\hline & ZSI & $\mathrm{SD}$ & $\mathrm{MD}$ & $\mathrm{MD}$ & $\mathrm{MD}$ & MW & MW & MW & $\mathrm{N}$ & 76 \\
\hline & & 15 & 10 & 10 & 10 & 10 & 10 & 10 & 1 & \\
\hline \multirow[t]{4}{*}{ Urmia } & SPI & $\mathrm{SD}$ & $\mathrm{MD}$ & ED & $\mathrm{N}$ & MV & MW & MW & $\mathrm{N}$ & 77 \\
\hline & & 15 & 10 & 20 & 1 & 10 & 10 & 10 & 1 & \\
\hline & ZSI & $\mathrm{MD}$ & $\mathrm{MD}$ & $\mathrm{MD}$ & $\mathrm{MD}$ & VW & VW & VW & $\mathrm{N}$ & 86 \\
\hline & & 10 & 10 & 10 & 10 & 15 & 15 & 15 & 1 & \\
\hline \multirow[t]{4}{*}{ Zanjan } & SPI & ED & $\mathrm{MD}$ & $\mathrm{SD}$ & ED & $\mathrm{N}$ & $\mathrm{N}$ & $\mathrm{N}$ & $\mathrm{N}$ & 69 \\
\hline & & 20 & 10 & 15 & 20 & 1 & 1 & 1 & 1 & \\
\hline & ZSI & $\mathrm{SD}$ & $\mathrm{MD}$ & $\mathrm{MD}$ & $\mathrm{SD}$ & MW & MW & MW & $\mathrm{N}$ & 81 \\
\hline & & 15 & 10 & 10 & 15 & 10 & 10 & 10 & 1 & \\
\hline \multirow[t]{2}{*}{ All stations } & SPI & 75 & 45 & 65 & 56 & 31 & 13 & 13 & 4 & 302 \\
\hline & ZSI & 55 & 40 & 45 & 50 & 50 & 45 & 50 & 4 & 339 \\
\hline
\end{tabular}

*Drought conditions: ED (extremely dry); SD (severely dry); MD (moderately dry); N (normal); MW (moderately wet); VW (very wet).

predicted at all stations by SPI and ZSI.Other results in table 6 showed that in the prediction of worst drought years, SPI was more acceptable,whereas ZSI was better in the wettest years. In other words, SPI has shown the worst drought years under more strict conditions and inversely,
ZSI has shown the wettest years under best wetness conditions. The total score of SPI and ZSI at all stations was 302 and 339, respectively, and thus, the ZSI was more capable of detecting the drought and wetness conditions (table 6). 


\section{Conclusion}

In spite of the scale and climatic diversity of Iran, almost all parts of this country are susceptible to drought, although to different extents. Therefore, drought characteristics of every region of this country need to be monitored and studied (Osmani 2009). Over the years, a number of prediction methods have been proposed for the evaluation of the probability of hydrological-meteorological variables or drought indices. Notable among these methods are the time-series modelling and the GP modelling, which were used in this study. In this study, the precipitation data recorded in four stations of northwestern Iran over the period 1960-2014 were used to develop the time-series and GP models. The predictions of these models for a 10-yr period were then compared with the observed data to evaluate their performance. The results of the comparison showed that although both models have acceptable accuracy in predicting annual precipitation, the time-series models have a lower error (RMSE) and higher efficiency (NS) than the GP model. Therefore, AR and PARMA models were chosen as the superior models for annual and monthly series, respectively, and were used to predict the annual precipitation, and thus, drought conditions of the studied stations for the next $10 \mathrm{yr}$ were obtained. According to the obtained SPI and ZSI values, in the studied stations, more than $60 \%$ of then years and months of the studied period have close to normal condition.

In all stations, SPI and ZSI values obtained for the future period (2014-2024) were lower than the values observed in the historical period (19602014). This decrease in drought indices values in the future period means that weather condition of the studied region will move towards more severe droughts. Comparison of the two indices showed that at all stations, SPI drought values were less than ZSI values.

The results obtained for the entire period (historical and prediction) also showed that given the current precipitation trends, the droughts are increasing in both severity and numbers. These results portray an unfavourable climatic future for the studied region. The results indicate a lower potential for the use of water in future years and, like many other studies in this field, emphasise the necessity of water conservation in all sectors, especially in agriculture. These results may encourage and aid the relevant authorities to adopt more effective policies in regard to water resource management and water conservation.

\section{Acknowledgements}

The authors wish to thank the I.R. of Iran Meteorological Organisation for useful information and data. Also, we would like to thank the Natural Resources and Earth Sciences Faculty of University of Kashan for providing helpful facilities that have led to significant improvement in this research results.

\section{References}

Ahmadi F, Dinpajhoh Y, Fakheri Fard A, Khalili K and Darbandi S 2015 Comparing nonlinear time series models and genetic programming for daily river flow forecasting (Case study: Barandouz-Chai River); J. Water Soil Conserv. 22(1) 151-169 (in Persian), http://jwsc.gau.ac.ir/ article_2363.html.

Akhtari R, Morid S, Mahdian M H and Smakhtin V 2009 Assessment of areal interpolation methods for spatial analysis of SPI and EDI drought indices; Int. J. Climatol. 29 135-145, https://doi.org/10.1002/joc.1691

Alvisi S, Mascellani G, Franchini M and Bardossy A 2006 Water level forecasting through fuzzy logic and artificial neural network approaches; Hydrol. Earth Syst. Sci. 10 1-17, https://doi.org/10.5194/hess-10-1-2006.

American Meteorological Society 1997 Policy statement: Meteorological drought; Bull. Am. Meteorol. Soc. $78847-$ 849.

Aytek A and Asce M 2008 An application of artificial intelligence for rainfall runoff modeling; J. Earth Syst. Sci. 117(2) 145-155, 10.1007/s12040-008-0005-2.

Bazrafshan O, Salajegheh A, Bazrafshan J, Mahdavi M and Fatehi Maraj A 2015 Hydrological drought forecasting using ARIMA models (Case Study: Karkheh Basin); Ecopersia 3(3) 1099-1117, http://ecopersia.modares.ac. ir/article_14033.html.

Borelli A, DeFalco I, Della C A, Nicodemi M and Trautteur G 2006 Performance of genetic programming to extract the trend in noisy data series; Physica A 370 104-108, https://doi.org/10.1016/j.physa.2006.04.025.

Danandeh Mehr A, Kahya E and Yerdelen C 2014 Linear genetic programming application for successive-station monthly streamflow prediction; Comput. Geosci.-Uk. 70 63-72, https://doi.org/10.1016/j.cageo.2014.04.015.

Dogan S, Berktay A and Singh V P 2012 Comparison of multi-monthly rainfall-based drought severity indices, with application to semi-arid Konya closed basin, Turkey; J. Hydrol. 470-471 255-268, https://doi.org/10.1016/j. jhydrol.2012.09.003, https://doi.org/10.1016/j.wace.2016. 11.005.

Edwards D C and Mckee T B 1997 Characteristics of 20th century drought in the United States at multiple time scales; Atmospheric Science Paper No. 634. 
Climatology Report No. 97(2), http://ccc.atmos. colostate.edu/edwards.pdf

Escalante-Sandoval C and Nuñez-Garcia P 2017 Meteorological drought features in northern and northwestern parts of Mexico under different climate change scenarios; J. Arid Land 9(1) 65-75, https://doi.org/10.1007/ s40333-016-0022-y

Guven A 2009 Linear genetic programming for time-series modeling of daily flow rate; J. Earth Syst. Sci. 118(2) 157-173, https://doi.org/10.1007/s12040-009-0022-9.

Han P, Wang P, Zhang S and Zhu D 2010 Drought forecasting based on the remote sensing data using ARIMA models; Math. Comput. Model 51 1398-1403, https://doi. org/10.1016/j.mcm.2009.10.031.

Hassanzadeh Y, Abdi Kordani A and Fakheri Fard A 2012 Drought forecasting using genetic algorithm and conjoined model of neural network-wavelet; Bimon. J. Water Wastewater 23(3) 48-59 (in Persian), http:// www.wwjournal.ir/article_1936_en.html.

Jain V K, Pandey R P, Jain M K and Byun H R 2015 Comparison of drought indices for appraisal of drought characteristics in the Ken River Basin; Weather Climate Extremes 8 1-11, https://doi.org/10.1016/j.wace.2015.05. 002.

Javanmard S., Emamhadi M., BodaghJamali J., Didehvaras A. 2017 Spatial-temporal analysis of drought in Iran using SPI during a long-term period; Earth Sciences 6(2) 15-29. https://doi.org/10.11648/j.earth.20170602.12

Khalili K, Tahoudi M N, Mirabbasi R and Ahmadi F 2016 Investigation of spatial and temporal variability of precipitation in Iran over the last half century; Stoch. Env. Res. Risk A 30(4) 1205-1221, https://doi.org/10.1007/ s00477-015-1095-4.

Krause P, Boyle D P and Base F 2005 Comparison of different efficiency criteria for hydrological model assessment; Adv. Geosci. 5 89-97, https://doi.org/10.5194/ adgeo-5-89-2005.

Mahsin M, Yesmin A and Monira B 2012 Modeling rainfall in Dhaka division of Bangladesh using time series analysis; J. Math. Model. Appl. 1(5) 67-73, http://proxy.furb.br/ ojs/index.php/modelling/article/view/2331.

Maity R, Suman M and Verma N K 2016 Drought prediction using a wavelet based approach to model the temporal consequences of different types of droughts; J. Hydrol. 539 417-428, https://doi.org/10.1016/j.jhydrol.2016.05.042.

Makkeasorn A, Chang N B and Zhou X 2008 Short-term streamflow forecasting with global climate change implications - A comparative study between genetic programming and neural network models; J. Hydrol. 352 336-354, https://doi.org/10.1016/j.jhydrol.2008.01.023.

Marco J B, Harboe R and Salas J D (eds) 2012 Stochastic hydrology and its use in water resources systems simulation and optimization, Vol. 237, Springer Science \& Business Media, Netherlands, p. 473, https://doi.org/10. 1007/978-94-011-1697-8.

Maybank J, Bonsai B, Jones K, Lawford R, O’brien E G, Ripley E A and Wheaton E 1995 Drought as a natural disaster; Atmos. Ocean 33(2) 195-222, https://doi.org/ 10.1080/07055900.1995.9649532.

McCuen R H 1989 Hydrologic analysis and design; Prentice Hall, Inc., Englewood cliffs, New Jersey.
McKee T, Doesken N and Kleist J 1993 The relationship of drought frequency and duration to time scales; In: Proceedings of the 8th, Boston, pp. 179-184, citeulikearticle-id:14027580.

Meher J and Jha M 2013 Time-series analysis of monthly rainfall data for the Mahanadi River Basin, India; Sci. Cold Arid Regions 5(1) 0073-0084, https://doi.org/10. 3724/SP.J.1226.2013.00073

Modarres R 2007 Streamflow drought time series forecasting; Stoch. Environ. Res. Risk A 21 223-233, https://doi.org/ 10.1007/s00477-006-0058-1.

Momani M and Naill P E 2009 Time series analysis model for rainfall data in Jordan: Case study for using time series analysis; Am. J. Environ. Sci. 5(5) 599-604, https://doi. org/10.3844/ajessp.2009.599.604.

Morid S, Smakhtin V and Moghaddasi M 2006 Comparison of seven meteorological indices for drought monitoring in Iran; Int. J. Climatol. 26 971-985, https://doi.org/10. 1002/joc. 1264 .

Osmani L 2009 SPI application for investigating of drought frequency, intensity and extent in northwest of Iran; In: The second national conference on drought effects/management (DEM), Agricultural and Natural Resources, Research Center, Isfahan, Iran, pp. 20-21, May, 2009 (in Persian).

Parsafar N and Maroufi S 2009 Meteorological drought indices efficiency in drought risk management of Orumiyeh area; In: Iranian national conference on water crisis in agriculture and natural resources, Azad Islamic University of Shahre Rey, Iran, 4 November 2009. In Persian.

Paulo A A, Ferreira E, Coelho C and Pereira L S 2005 Drought class transition analysis through Markov and loglinear models, an approach to early warning; Agric. Water Manag. 77(1-3) 59-81, https://doi.org/10.1016/j.agwat. 2004.09.039.

Rajurkara M, Kothyarib U and Chaube U 2004 Modeling of the daily rainfall-runoff relationship with artificial neural network; J. Hydrol. 285 96-113, https://doi.org/10.1016/ j.jhydrol.2003.08.011.

Saada N 2014 Time series modeling of monthly rainfall in arid areas: Case study for Saudi Arabia; Am. J. Environ. Sci. 10(3) 277, https://doi.org/10.3844/ajessp.2014.277. 282.

Salahi B., Faridpour M. 2016 Spatial analysis of climatic drought in North West of Iran using spatial autocorrelation statistics. Jsaeh 3(3) 1-20, http://jsaeh.khu.ac.ir/ article-1-2617-en.html

Salas J D, Delleur J W, Yevjevich V and Lane W L 1980 Applied modeling of hydrologic time series; Water Resource Publications, Littleton, CO, USA, 484 Papers.

Shao Q, Wong H, Li M and Ip W C 2009 Streamflow forecasting using functional-coefficient time series model with periodic variation; J. Hydrol. 368(1-4) 88-95, https:// doi.org/10.1016/j.jhydrol.2009.01.029.

Smakhtin V U and Hughes D A 2007 Automated estimation and analyses of meteorological drought characteristics from monthly rainfall data; Environ. Model. Softw. 22(6) 880-890, https://doi.org/10.1016/j.envsoft.2006.05.013.

Suryabhagavan K V 2017 GIS-based climate variability and drought characterization in Ethiopia over three decades; Weather Clim. Extrem. 15 11-23. 
Wei W S W 2006 Time series analysis - univariate and multivariate methods; (2nd edn), Pearson publication, USA, p. 614, https://doi.org/10.1093/oxfordhb/ 9780199934898.013.0022.

Wu H, Hayes M J, Weiss A and Hu Q I 2001 An evaluation of the standardized precipitation index, the China-Z Index and the statistical Z-score; Int. J. Climatol. 21 745-758, https://doi.org/10.1002/joc.658.

Zahedi M, Sarisarraf B and Jame'Ee J 2006 Rain modeling in Tabriz and Oroumiyeh stations; J. f. Geography. Reg. Dev. 4(7) 1-16, https://doi.org/10.22067/geography.v4i7. $4164 \mathrm{~A}$.

Corresponding editor: RAJIB MAITY 